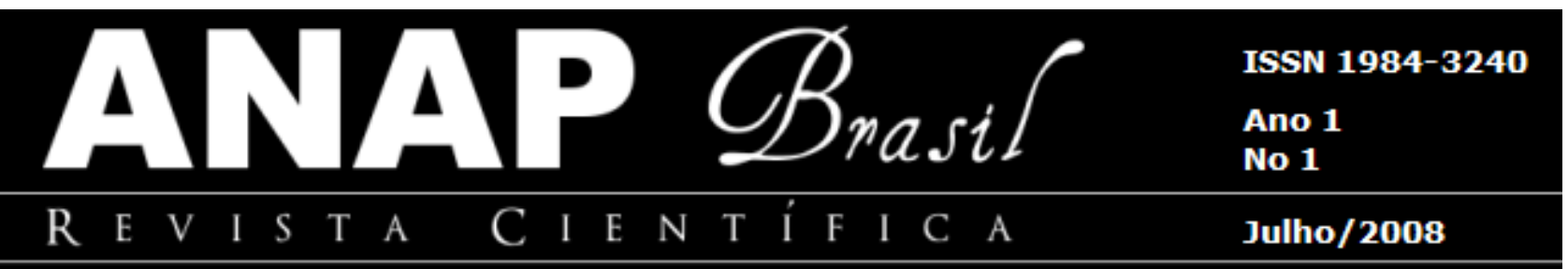

\title{
A IMPORTÂNCIA DOS PRINCÍPIOS CONSTITUCIONAIS AMBIENTAIS NA EFETIVAÇÃO DA PROTEÇÃO DO MEIO AMBIENTE
}

Juliana Xavier Fernandes Martins ${ }^{1}$

Resumo: Os princípios constitucionais ambientais surgiram como conseqüência prática das Convenções Internacionais para o Meio Ambiente promovidas pela ONU. Especialmente a ocorrida em 1972, em Estocolmo na Suécia que consagrou o surgimento do Direito Ambiental no âmbito mundial. Os princípios, especialmente o do Desenvolvimento Sustentável, da Precaução e do Poluidor Pagador ganharam ênfase temática no cenário da proteção ambiental tanto para as presentes como para as futuras gerações. Existe no arcabouço jurídico nacional, uma série de mecanismos de implementação destes princípios. O licenciamento ambiental e os estudos prévios de impactos ambientais, além dos instrumentos de controle de qualidade são exemplos desses mecanismos. Contudo, hodiernamente vislumbra-se um cenário de inexpressiva aplicabilidade desses princípios. Nota-se um total desconhecimento além de falta de vontade política em sua efetiva aplicação para uma real e necessária proteção do meio ambiente e para que efetivamente cumpram o seu papel, o de garantir a vida com dignidade.

Palavras-chave: Princípios. Aplicabilidade. Proteção

\footnotetext{
${ }^{1}$ Bacharel em Direito pela Universidade Estadual Paulista Julio de Mesquita Filho - Unesp, Mestre em Direito Ambiental pela Universidade Estadual Paulista Julio de Mesquita Filho - Unesp, Professora Universitária. Advogada
} 


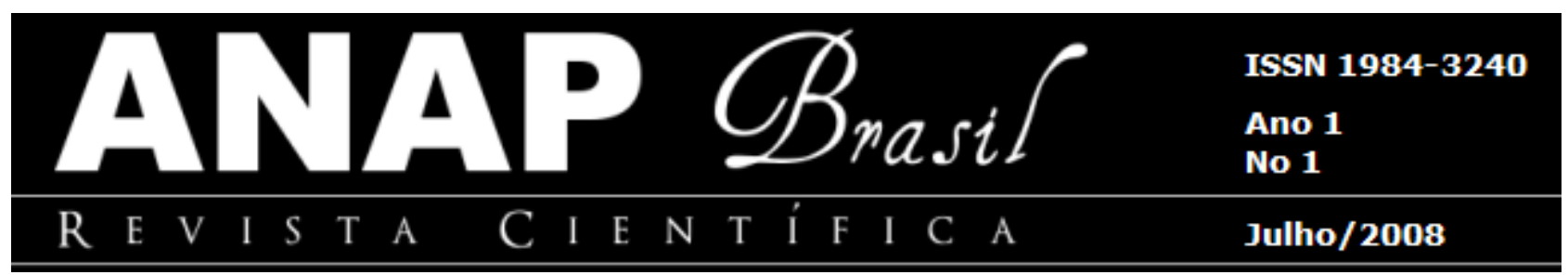

\section{INTRODUÇÃO}

No Brasil, a questão ambiental passou a ter relevância jurídica constitucional, pois, o direito de viver num ambiente ecologicamente equilibrado foi erigido à categoria de Direito Humano fundamental pela constituição Federal de 1988.

Buscou o legislador orientar o desenvolvimento e a aplicação de políticas públicas ambientais que servem como instrumento fundamental de proteção ao meio ambiente e, consequentemente, à vida humana.

O Direito ambiental, tendo o seu entendimento sob o prisma de uma ciência dotada de autonomia científica, apesar de seu caráter interdisciplinar, obedece, na aplicação de suas normas, a princípios específicos de proteção ambiental.

Neste sentido, os princípios que informam o direito ambiental têm escopo fundamental de proteção ao meio ambiente e, assim, tentar garantir melhor qualidade de vida a toda coletividade.

Os princípios ambientais especialmente o Princípio do Desenvolvimento Sustentável, Princípio do Poluidor pagador, Princípio da Prevenção e o Princípio da cooperação, estão instrumentalizados no quadro normativo de forma que a sua aplicabilidade está demonstrada através de mecanismos de implementação das políticas nacionais do meio ambiente.

O controle de qualidade, estudos ambientais e o licenciamento ambiental são exemplos desta instrumentalidade.

Ocorre que referidos princípios ainda são incipientes na realidade brasileira tanto no que refere-se a sua aplicabilidade quanto no que se refere ao seu conhecimento. Não há responsabilidade do Poder Publico de proteção e da coletividade em defender .

Os princípios de Direito Ambiental objetivam a proteção da vida humana e garantia plena em todos seus aspectos, hoje e para as futuras gerações e, para tanto necessitam de sua efetiva aplicação. 


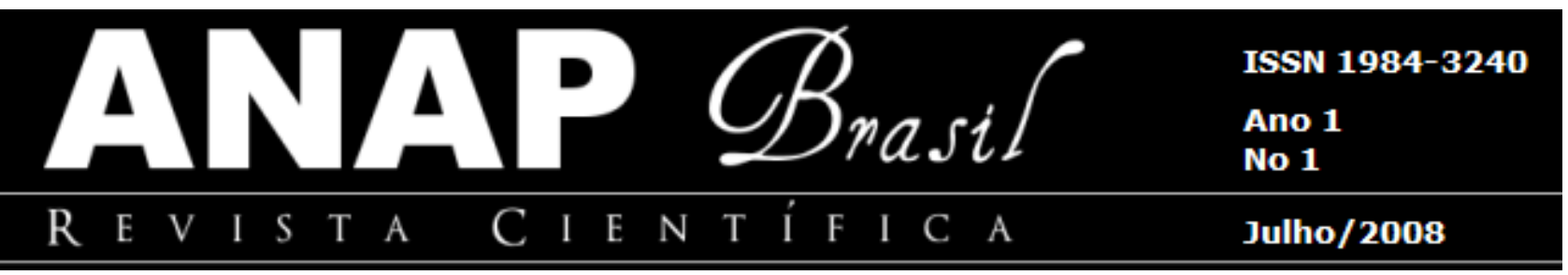

\section{AS CONFERÊNCIAS MUNDIAIS E O SURGIMENTO DOS PRINCÍPIOS AMBIENTAIS}

O grande marco internacional para a conscientização ambiental ficou selado com a realização da primeira conferência mundial ambiental. Esse ficou conhecida como a Conferência de Estocolmo de 1972 e teve a participação de vários Estados-membros das organizações governamentais e não-governamentais (ONGs).

Como resultado efetivo, foi elaborado um documento que ficou conhecido como a Declaração de Estocolmo (Declaração das Nações Unidas sobre o Meio Ambiente). documento contém os famosos 26 Princípios precursores na tomada de consciência ambiental internacional. Pode-se afirmar, com certeza que, a partir desse evento, foi conquistado um lugar permanente para o meio ambiente na agenda global e uma crescente consciência popular.

Nesse aspecto bem se pronuncia Guido Fernando Silva Soares ao afirmar que

A Declaração sobre o Meio ambiente Humano, adotada em Estocolmo pela Conferência das Nações Unidas sobre o Meio Ambiente Humano, pode ser considerada como um documento com a mesma relevância para o Direito Internacional e para a Diplomacia dos Estados que a Declaração Universal dos Direitos do Homem (adotada pela Assembléia Geral da ONU em 10.12.1945). Na verdade, ambas Declarações têm exercido o papel de verdadeiros guias e parâmetros na definição dos princípios mínimos que devem figurar tanto nas legislações domésticas dos Estados, quanto na adoção dos grandes textos do Direito Internacional da atualidade. ${ }^{2}$

Houve ainda como resultado concreto desse encontro a criação de um organismo dedicado ao meio ambiente para atuar, junto à ONU, o denominado Programa das Nações Unidas sobre o Meio Ambiente - PNUMA.

Juraci Perez Magalhães nos afirma, com propriedade, que a Conferência de Estocolmo "trouxe novos conceitos de bem-estar para a humanidade e traçou o caminho a ser trilhado pela economia no futuro, dando à preservação ambiental uma dimensão universal"3 ${ }^{3}$ posição esta reafirmada na Eco-92.

Decorridos vinte anos, verificou-se um verdadeiro avanço na degradação

SOARES, op. cit., p. 55, nota 2.

MAGALHÃES, op. cit., p. 689, nota 1. 


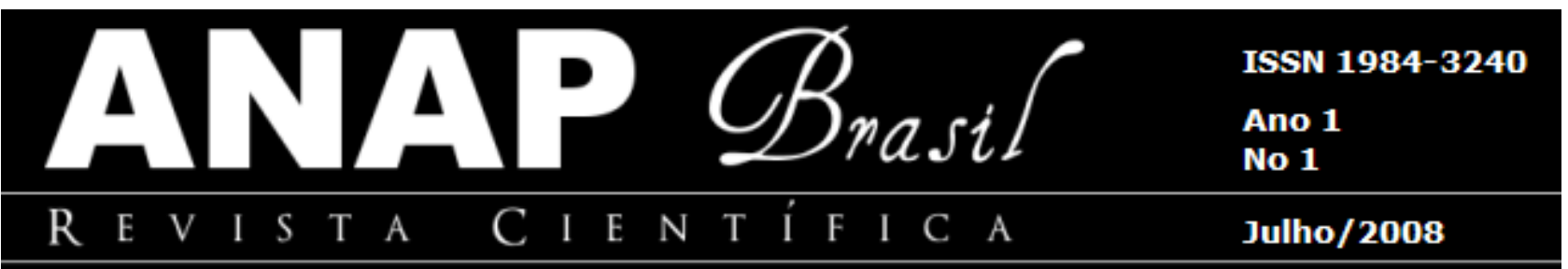

ambiental no âmbito mundial, notadamente pela destruição dos bens naturais, bem como no aumento da poluição.

A Assembléia das Nações Unidas decidiu pela convocação de uma nova conferência, a II Conferência das Nações Unidas para o Meio Ambiente e Desenvolvimento, conhecida como a ECO-RIO 92, realizada no Rio de Janeiro, de $1^{\circ}$ a 12 de junho de 1992, com a participação de 178 Governos e a presença de mais de 100 Chefes de Estado.

Essa foi considerada a maior reunião internacional até então realizada pelas Nações Unidas, repleta de significados políticos. Nas palavras de Guido, "considerada um dos pontos culminantes no aperfeiçoamento das normas de proteção ambiental."

Dessa conferência, surgiu um importante documento, denominado a Declaração do Rio sobre Meio Ambiente e Desenvolvimento, contendo uma gama de 27 princípios de interesse ambiental, entre eles, o conceito de desenvolvimento sustentado.

Outro resultado expressivo foi a aprovação da Agenda 21, "um dos principais feitos da ECO/92, documento que traça as ações político-normativas a serem adotadas pelos Estados até o século XXI"5, portanto, documento que definiu metas a serem cumpridas pelos países participantes. Ele marcou o início de uma verdadeira evolução dinâmica e radical.

Assim "O Princípio do desenvolvimento sustentável foi adotado na Declaração do Rio e na Agenda 21 como meta a ser buscada e respeitada por todos os países."

Trinta anos após a Conferência das Nações Unidas sobre Desenvolvimento Humano, em Estocolmo, e dez anos após a Eco- 92, ocorrida no Rio de Janeiro; a Cúpula Mundial sobre Desenvolvimento Sustentável ocorreu em

Johannesburg, na África do Sul, entre os dias 26 de agosto a 4 de setembro de 2002, e ficou conhecida como a Rio + 10.

Assim, o ano de 2002 certamente já entrou para a história do direito ambiental, tal como os anos de 1972 e 1992 e, com o passar dos anos, poder-se-á concluir com certeza se os seus resultados serão de verdadeira concretude ao meio ambiente ou somente retórica da política ambiental internacional.

SOARES, op. cit., p. 77 , nota 2.

Ibidem, p. 67.

MILARÉ, Edis. Direito do ambiente: um direito adulto. Revista de Direito Ambiental, São Paulo, ano 4, n. 15, p. 34-55, jul./set. 1999. p. 48. 


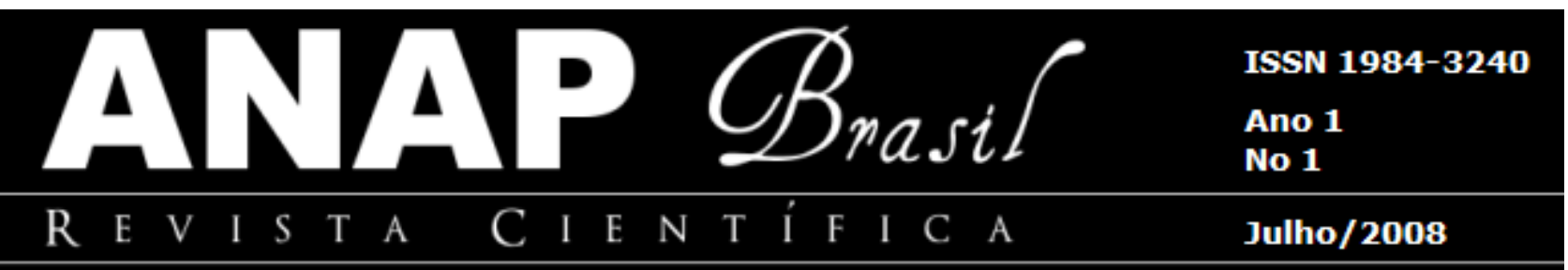

O evento teve a participação de governos, organismos multilaterais e organizações não-governamentais. O intuito desse encontro foi o de estabelecer objetivos e prazos rígidos para a efetiva proteção ao meio ambiente, ou seja, estabelecer um plano de ação para a Agenda 21, anteriormente firmada em 1992 no Rio de Janeiro.

Como resultado, foi firmada por 190 países signatários a Declaração de Johanesburgo. Nesse documento, os Estados se comprometeram a colaborar com o desenvolvimento sustentável, tendo como base o progresso econômico, justiça social e proteção do meio ambiente.

Frise-se aqui os comentários do então secretário do meio ambiente do Estado de São Paulo José Goldemberg, "O que houve de diferente para o Brasil, em Johanesburgo, é que o nosso país não era apenas um participante entre muitos, mas sim, o proponente de uma das propostas mais importantes e criativas."

Em síntese, ao analisar a história, vislumbra-se a grande importância que as Conferências mundiais trouxeram para a tutela do meio ambiente tanto no cenário internacional, como para o Brasil.

Os princípios e as declarações que surgiram pela primeira grande Conferência mundial ambiental foram, sem dúvida, a mola propulsora que inspirou os nossos legisladores a internalizar os princípios ambientais, promulgando a Lei 6.938 de 31 de agosto de 1981, conhecida como a Lei da Política Nacional do Meio Ambiente.

\section{A PRINCIPIOLOGIA AMBIENTAL}

Durante muito tempo a Filosofia e a Teoria Geral do direito discutiram acerca da normativa ou não dos princípios, buscando superar a antinomia ente o direito natural e o direito positivo.

Hoje admitindo-se definitivamente os princípios como normas, mais precisamente normas-valores. A norma é entendida como gênero cujas espécies são os princípios e regras, sendo ambos fundamentos para juízos concretos de dever.

GOLDEMBERG, José. Johannesburg, vitória ou derrota? O Estado de São Paulo, São Paulo, 5 set. 2002. Caderno Geral, p. A-12. 


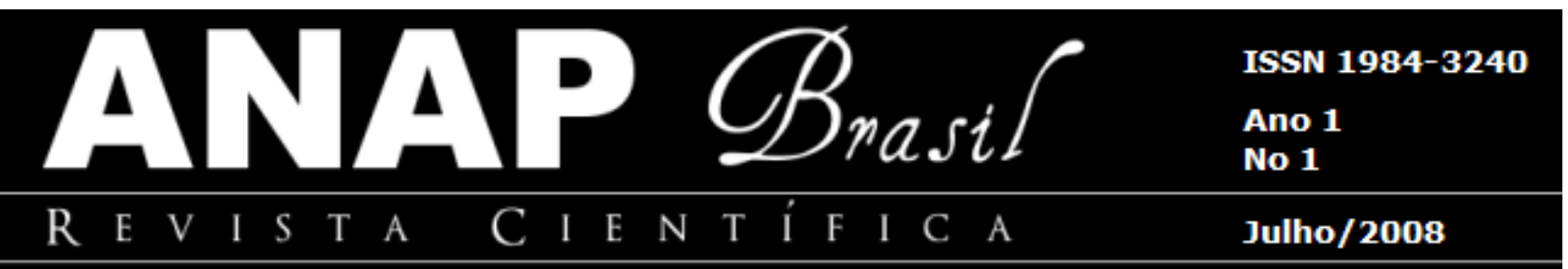

A importância vital que os princípios assumem para os ordenamentos jurídicos se torna cada vez mais evidente, sobretudo se lhes examinarmos a sua função e presença no corpo das constituições contemporâneas, onde aparecem como os pontos axiológicos de mais alto destaque e prestígio com que fundamentar a hermenêutica dos tribunais e legitimidade dos preceitos de ordem constitucional.

Dentro das novas tendências abarcadas pelo Direito Ambiental, temos o surgimento dos princípios.

Princípios de uma ciência, segundo José Cretella Júnior, "são proposições básicas, fundamentais, típicas, que condicionam todas as estruturas subseqüentes."8

As convenções internacionais inspiraram o surgimento de vários princípios que, sem poder legal, vieram informar as nossas legislações e hoje vários princípios estão inseridos no nosso arcabouço legal.

Os princípios ambientais encontram-se, pois, no ordenamento jurídico, com função de orientar a atuação do legislador e dos poderes públicos além de toda a sociedade na concretização e cristalização dos valores sociais, relativos ao meio ambiente, harmonizando as normas do ordenamento ambiental, direcionando a sua interpretação e aplicação, e ressaltando definitivamente a autonomia do Direito Ambiental, como ciência.

Consolidados no artigo 225 da Constituição Federal, destacam-se como princípios da Política Nacional do Meio Ambiente.

\section{O PRINCÍPIO DO DESENVOLVIMENTO SUSTENTÁVEL}

Sob o prisma do Princípio do Desenvolvimento Sustentado que trata de uma inovação ambiental, criando direitos para aqueles que ainda não nasceram, surgem os três princípios fundamentais abaixo tratados entre outros de fundamental importância que neste trabalho não são abordados:

a) Princípio da prevenção e precaução;

CRETELLA JÚNIOR. Comentários à Constituição brasileira de 1988. Rio de Janeiro: Forense Universitária, 1989. v. 1, p. 129. 


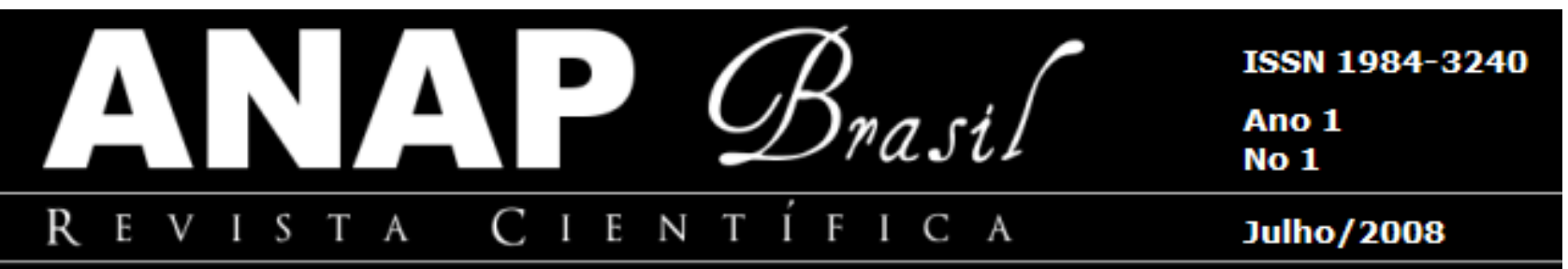

b) Princípio da participação e cooperação; e

c) Princípio do poluidor/pagador.

O Princípio do Desenvolvimento Sustentável teve a sua origem na Conferência Mundial Sobre o Meio Ambiente, ocorrida em 1972, em Estocolmo. O seu conteúdo e sua importância foram amplamente discutidos nas demais Conferências sobre o meio ambiente que ocorreram após a Conferência de Estocolmo, especialmente, na Conferência ocorrida no Brasil, na cidade do Rio de Janeiro em 1992, a conhecida EcoRio.

Com o advento da Carta Política de 1988, a preservação do meio ambiente passou a ser a palavra de ordem e o referido princípio foi elevado e institucionalizado no "caput" do art. 225.

O desenvolvimento sustentável é definido pela Comissão Mundial sobre Meio Ambiente e Desenvolvimento como "aquele que atende às necessidades do presente sem comprometer a possibilidade de as gerações futuras atenderem a suas próprias necessidades. ${ }^{9}$

A questão de usufruir corretamente dos recursos ambientais deve ser bem analisada, ou seja, o verbo usufruir traduz um direito; o advérbio corretamente conota o dever.

No princípio do direito ao desenvolvimento sustentável, direito e dever estão de tal forma imbricados que, mais do que termos relativos, são termos recíprocos, mutuamente condicionantes. Daí a legitimidade, a força e a oportunidade desse princípio como referência basilar do Direito do Ambiente. ${ }^{10}$

Esse fundamental Princípio tem como conteúdo central o proclame de um desenvolvimento que atenda às necessidades do presente sem comprometer as futuras gerações, observa-se, portanto uma inovação ambiental, pois cria-se direitos

para aqueles que ainda não nasceram.

COMISSÃO Mundial sobre Meio Ambiente e Desenvolvimento. Nosso futuro comum. 2. ed. Rio de Janeiro: Fundação Getúlio Vargas, 1991. p. 46 apud MILARÉ, op. cit., p. 48, nota 9.

10 Cf. MILARÉ, op. cit., p. 48, nota 9. 


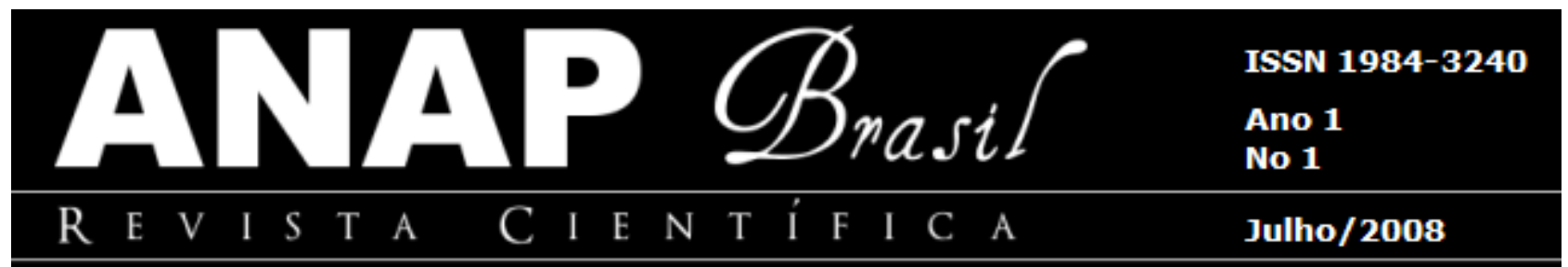

Neste princípio, talvez mais do que em outros, surge tão evidente a reciprocidade entre direito e dever, porquanto o desenvolver-se e usufruir de um planeta plenamente habitável não é apenas direito, e dever precípuo das pessoas e da sociedade. Direito e dever como contrapartidas inquestionáveis. ${ }^{11}$

O seu surgimento é corolário da constatação que os recursos naturais são esgotáveis, finitos, tornando-se inadmissível que as atividades econômicas desenvolvamse alheias a esse fato. O mundo então, através de organismos governamentais e não governamentais veio a observar que a contínua degradação ambiental, da forma como ocorrera nos séculos XIX e meados do século XX afetaria a capacidade econômica frente à escassez dos recursos naturais, verificando-se que não mais seria possível à nossa geração bem como às vindouras, desfrutar da vida com qualidade.

Ora é sabido que as atividades econômicas, na maioria das vezes, representam alguma degradação ambiental, assim, o que se procura com a implementação desse princípio é minimizar a degradação; buscar atividades que sejam desenvolvidas lançando-se mão dos instrumentos existentes e adequados para uma menor degradação possível.

Tanto assim é verdade que a Constituição Federal estabelece que

a ordem econômica, fundada na livre iniciativa (sistema de produção capitalista) e na valorização do trabalho humano (limite ao capitalismo selvagem) deverá regerse pelos ditames da justiça social, respeitando o princípio da defesa do meio ambiente, contido no inciso VI do artigo $170 .^{12}$

Concluí-se, portanto, que para a sua aplicabilidade exige um adequado planejamento territorial, que tenha em conta os limites da sustentabilidade.

O reconhecimento do direito a um meio ambiente sadio configura-se, na verdade, como extensão do direito à vida, quer sob o enfoque da própria existência física e saúde

11 MILARÉ, op. cit., p. 47, nota 9.

12 FIORILLO, op. cit., p. 26 , nota 23.

Art. 170. A ordem econômica, fundada na valorização do trabalho humano e na livre iniciativa, tem por fim assegurar a todos existência digna, conforme os ditames da justiça social, observados os seguintes princípios:

[...] IV - defesa do meio ambiente; [...]. 


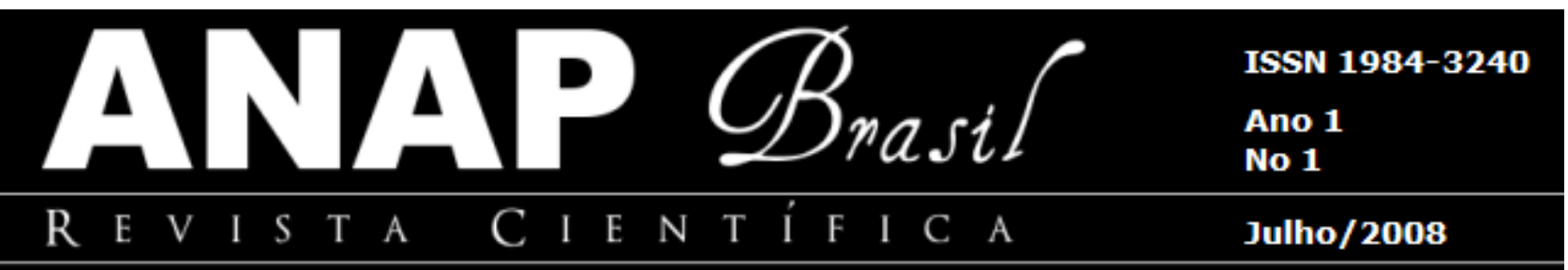

dos seres humanos, quer quanto ao aspecto da dignidade desta existência - a qualidadede-vida -, que faz com que valha a pena viver. ${ }^{13}$

\section{O PRINCÍPIO DA PREVENÇÃO E PRECAUÇÃO}

O Princípio da prevenção e da precaução está previsto na Declaração de Estocolmo. O conteúdo dos Princípios 14, 15 e 17, exerceram grande influência no plano da ordem jurídica interna de nosso país, saindo efetivamente do conteúdo pragmático para uma a efetiva exigência legal ambiental, refletida na Lei 6.938/81, artigo $9^{\circ}$, inciso IV, que criou a necessidade da emissão da Licença Prévia, para todas as atividades potencialmente poluidoras.

Esse princípio foi abraçado como diretriz ambiental básica desde a Declaração do Meio Ambiente de Estocolmo(1972), vindo, a partir de lá, a orientar todas as políticas ambientais moderna, notadamente marcadas por uma incessante busca de novas tecnologias, capazes de afastar os riscos de danos ambientais. ${ }^{14}$

Contudo, foi sim na Conferência das Nações Unidas sobre o Meio Ambiente e Desenvolvimento, ocorrida no Rio de Janeiro em 1992, que o principio foi efetivamente consagrado. É importante "consignar que o Brasil foi um dos responsáveis diretos pela formulação dessa importante diretriz relacionada à proteção do meio ambiente". ${ }^{15}$

Esta previsto no item 15 da Declaração de princípios:

De modo a proteger o meio ambiente, o princípio da precaução deve ser amplamente observado pelos Estados, de acordo com suas capacidades. Quando houver ameaça de dano sérios ou irreversíveis, a ausência de absoluta certeza cientifica não deve ser utilizada como razão para postergar medidas eficazes e economicamente viáveis para prevenir a degradação ambiental.

Cf. TRINDADE, op. cit., p. 76, nota 31.

1 Cf. FIORILLO; RODRIGUES, op. cit., p. 140, nota 39.

15 MIRRA, Álvaro Luiz Valery. Direito ambiental: o princípio da precaução e sua aplicação judicial. Revista de Direito Ambiental, São Paulo, ano 6, n. 21, p. 92-102, jan./mar. 2001. p. 96. 


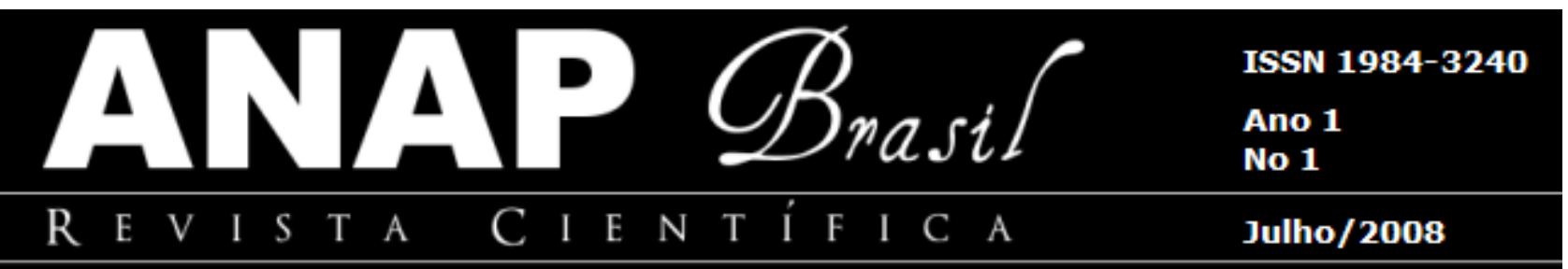

Por outro lado, o Direito Brasileiro já na Constituição Federal de 1988, no Capítulo sobre o Meio Ambiente já havia institucionalizado como parte integrante do ordenamento brasileiro, ao preceituar no caput do art. 225, o dever do Poder Público e da coletividade de proteger e preservar o meio ambiente para as presentes e futuras gerações.

Assim, o Princípio da precaução, atua como viga mestra, na luta pela preservação do meio ambiente, ou seja, trata-se de um dos princípios gerais do nosso direito ambiental.

Cite-se aqui os principais textos legais que trazem consigo o Princípio da precaução:

a) Constituição Federal art. 225 "caput"e seus parágrafo $1^{\circ}$, incisos I, III, IV e parágrafo $6^{\circ}$;

b) Lei 6.938/81;

c) Resoluções Conama: 1/86; 237/97 e 279/01.

A experiência tem demonstrado que a atividade humana, para produzir alimentos e bens duráveis, interfere de forma direta no equilíbrio ecológico, tais como as atividades agropecuárias e atividades industriais. Assim, a precaução tornou-se um preceito fundamental uma vez que os danos são irreversíveis e irreparáveis e via de conseqüência este Princípio é considerado o sustentáculo do Direito Ambiental.

Nesse ponto, vale a lição de Édis Milaré:

[...] Precaução é substantivo do verbo precaver-se (do Latim prae=antes e cavere=tomar cuidado), e sugere cuidados antecipados, cautela para que uma atitude ou ação não venha a resultar em efeitos antecipados, cautela para que uma atitude ou ação não venha a resultar em efeitos indesejáveis. [...]. ${ }^{16}$

A partir da consagração do principio da precaução, o Direito brasileiro passou a ter outra orientação: houve uma total mudança no enfoque de sua aplicação, implementando o enfoque da prudência e da vigilância, diversamente da orientação até então proposta, que era o da tolerância. Nesse sentido, diante de controvérsias no plano científico com relação aos efeitos nocivos de determinada atividade sobre ambiente,

MILARÉ, op. cit., p. 44 , nota 9. 


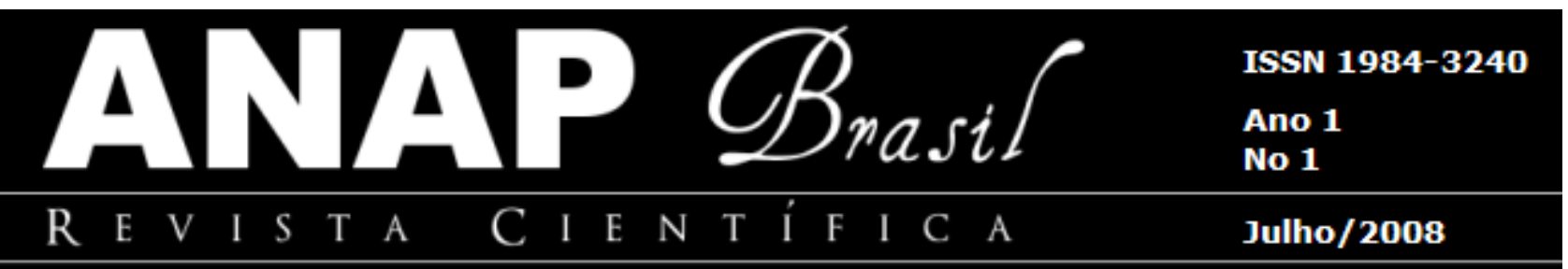

o principio da precaução autoriza a inviabilidade da implementação da atividade ou até mesmo o seu controle rígido, como meio de impedir a degradação do ambiente. ${ }^{17}$

Inserido como principio de ordem geral e norma de observância obrigatória, tem como conteúdo central a orientação que prever e prevenir é um dever de todos e não podem ser ignorados pelos legisladores, diante do seu compromisso protético, pelos administradores públicos e tampouco pelos aplicadores de nossos tribunais internos.

Os Instrumentos administrativos colocados à disposição para a implementação do princípio da prevenção são:

a) Licenças Ambientais: o licenciamento ambiental é novidade ambiental que aparece no Brasil no início da década de 70 nos termos da Resolução Conama 237/97, artigo $1^{\circ}$, inciso I

licenciamento ambiental é o procedimento administrativo pelo qual o órgão ambiental competente licencia a localização, instalação, ampliação e operação de empreendimentos e atividades utilizadoras de recursos ambientais consideradas efetiva ou potencialmente poluidoras ou aquelas que, sob qualquer forma, possam causar degradação ambiental, considerando as disposições legais e regulamentares e as normas técnicas aplicáveis ao caso.

O processo de licenciamento ocorre em três etapas, sucessivas: Licença Prévia, Licença de Instalação e Licença de Operação.

Mister frisar que há uma exigência previa à concessão das Licenças, assim, a legislação determina que se estabeleça a Avaliação de Impacto Ambiental(AIA) que vem a ser um estudo da significância do impacto ambiental de um determinado empreendimento ou atividade, sendo o Estudo Prévio de Impacto ambiental e o seu relatório (EIA/RIMA) um estudo mais completo e detalhado, diferentemente da legislação antiga que apenas reprimia a ação danosa, e ainda diante do perigo eminente.

"O Estudo Prévio de Impacto ambiental é considerado um dos instrumentos imprescindíveis de proteção jurídica do ambiente"18 ressaltando-se inclusive, que a sua previsão está expressa na Constituição Federal.

17 MIRRA, Álvaro Luiz Valery. Princípios fundamentais de direito ambiental. Revista de Direito Ambiental, São Paulo, ano 1, n. 2, p. 50-66, abr./jun. 1996. p.57.

18 BENJAMIN, op. cit., p. 60, nota 6. 


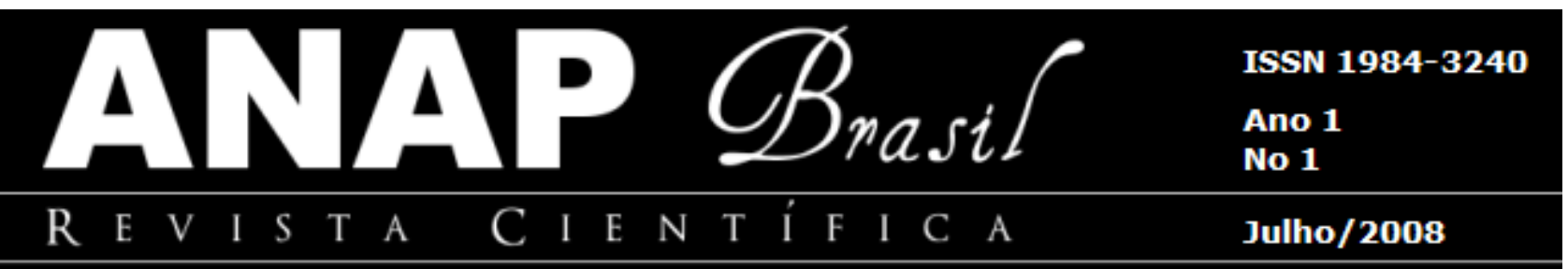

Verifica-se que os órgãos ambientais, baseando-se no princípio da precaução, tem negado a concessão de várias Licenças.

a) Mapeamento ecológico: trata de instrumento que possui a finalidade de identificar vegetais, animais, fontes de poluição, com o objetivo de conservação e controle ambiental através do Poder de Polícia.

b) Ordenamento territorial: o zoneamento é um dos instrumentos de política ambiental, trata-se de um procedimento de natureza geoeconômica que visa disciplinar e valorizar os diferentes tipos de áreas.

c) Imposição de fiscalização ativa: conferido ao Estado na busca de aplicação de medidas punitivas, exemplificativamente: advertências, multas pesadas, apreensão de produtos da flora e fauna, embargo da obra ou atividade.

d) Manejo ecológico: trata-se na verdade de produção com equilíbrio.

Nos Instrumentos fiscais colocados à disposição para a implementação nota-se a ocorrência de incentivos fiscais conferidos às atividades que atuem em parceria com o meio ambiente e que se utilizem de tecnologias limpas.

No que se refere aos instrumentos colocados à disposição do Poder Judiciário para a sua implementação, observa-se a prática à multiplicação de ações que venham a impedir a continuidade do evento danoso ou ajuizamento de ações com caráter preventivo. Verifica-se, portanto, a implementação da substituição do critério da certeza pelo critério da probabilidade.

Observa-se a contundente ação do Ministério Público e que de forma precursora tem pedido liminares, nas Ações Civis Públicas e os juízes as têm concedido, entendendo caracterizado o periculum in mora.

\section{O PRINCÍPIO DA PARTICIPAÇÃO E COOPERAÇÃO}

Esse princípio está expressamente mencionado no "caput" do artigo 225 da CF, consagrando na defesa do meio ambiente a atuação presente do Estado e da sociedade civil na proteção e preservação do meio ambiente, ao impor à coletividade e ao Poder Público tais deveres. 


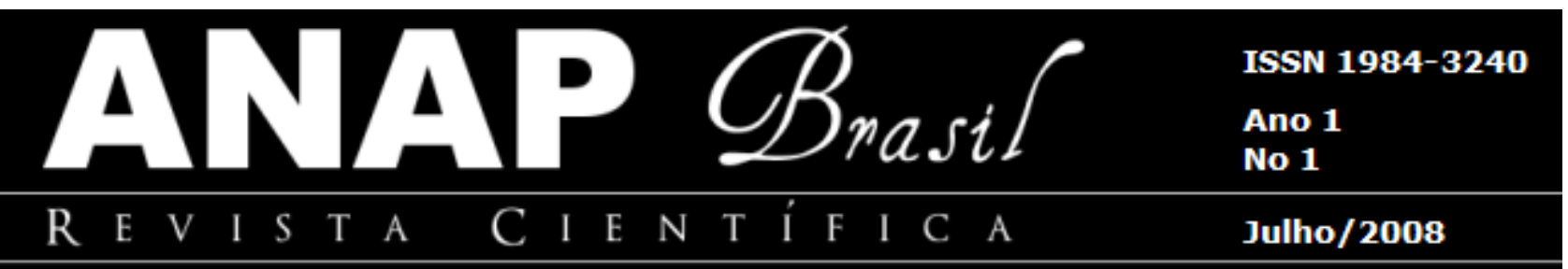

Por outro lado, tal princípio foi erigido já em 1972, na Conferência de Estocolmo que previu o "Princípio n. 17 - Deve ser confiada às instituições nacionais competentes a tarefa de planificar, administrar e controlar a utilização dos recursos ambientais dos Estados, com o fim de melhorar a qualidade do meio ambiente."

Refere-se oportuno ressaltar que a sua diretriz principal é o comprometimento ecológico. É o poder e dever conjunto do Poder Público e da coletividade com participação dos diferentes grupos sociais na formulação e execução da política ambiental.

Referido princípio está voltado diretamente para a cidadania e ainda se trata de um dos mais importantes agentes políticos transformadores das normas de gestão ambiental.

Em seu conteúdo, observa-se dois planos de atuação:

a) Informação - resulta no direito de acesso das pessoas às informações, preconizado no artigo $6^{\circ}$, parágrafo $3^{\circ}$ e $10^{\circ}$. da Lei de Política Nacional do Meio Ambiente e o dever do Estado em repassá-las.

b) Educação - oriunda do Principio 19 da Declaração de Estocolmo. Resulta do dever do Poder Público em promover à sociedade meio de educar os cidadãos, informando-lhes da necessidade e importância de se manter o equilíbrio do meio ambiente, para que se possa ter condições dignas de sobrevivência.Ora, somente a uma sociedade educada, com princípios de cidadania bem definidos que se poderá exigir dos diferentes grupos sociais a efetiva participação e cooperação na política ambiental.

Ressaltam-se alguns exemplos do princípio da educação ambiental na atuação legislativa, na própria lei no. 6938/81 e artigo 42 do Código Florestal.

Verifica-se, portanto, que o dever do Poder Público em promover a educação e a informação ambiental, tem sede constitucional e está expressamente abraçado, no seu artigo $225, \S 1^{\circ}$, VI. $^{19}$

\section{O PRINCÍPIO DO POLUIDOR PAGADOR E DA RESPONSABILIZAÇÃO}

19 Parágrafo $1^{\circ}$. Para assegurar a efetividade desse direito, incumbe ao Poder Público: $[\ldots]$ VI - promover a educação ambiental em todos os níveis de ensino e a conscientização pública para a preservação do meio ambiente; [...]. 


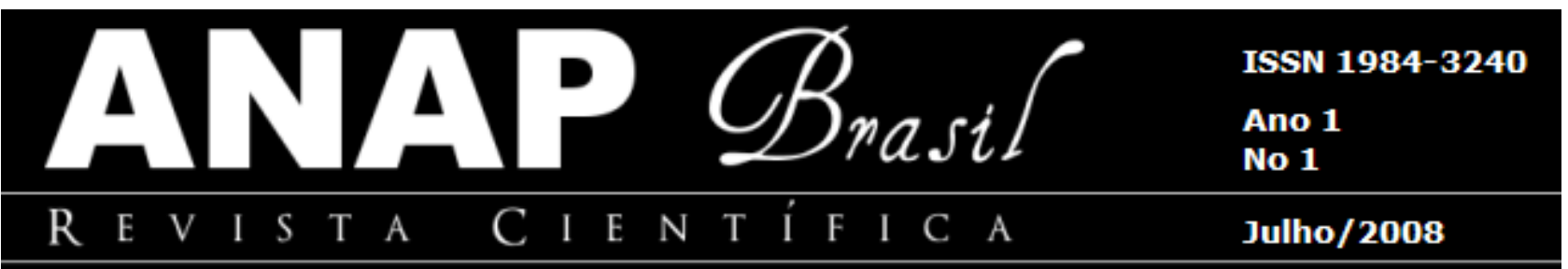

Esse princípio tal qual os demais princípios estudados nos tópicos anteriores, teve o seu nascedouro na década de 1970, com a tomada de consciência e preocupação de âmbito mundial e, encontra-se consolidado no item 16 da Declaração do Rio de Janeiro de 1992.

Em sua proposta central, propõe que aquele que degrada o meio ambiente tem o dever de recuperar ou indenizar, porém, o referido princípio reclama atenção, pois não traz consigo ao contrário do que possa parecer, o indicativo - pagar para poluir ou poluir mediante pagamento.

"Com a aplicação do princípio do poluidor-pagador, procura-se corrigir este custo adicionado à sociedade, impondo-se sua internalização. Por isto, este princípio é também conhecido como o princípio da responsabilidade."20

Reporta-se às palavras de Édis Milaré, "trata-se do princípio poluidor-pagador (polui, paga os danos), e não pagador-poluidor (pagou, então pode poluir). A colocação gramatical não deixa margem a equívocos ou ambigüidades na interpretação do princípio." 21

Bem se pronuncia Lise Vieira da Costa Tupiassu, "que este princípio indica que o poluidor deverá suportar o custo das medidas tomadas pelo poder Público para assegurar a preservação do meio ambiente."22

Dessa forma, em sua diretriz o princípio do poluidor-pagador traz consigo duas órbitas bem definidas de alcance e aplicação, uma de caráter preventivo que busca evitar a ocorrência de danos ambientais e outra de caráter repressivo, proclama que uma vez constatada a ocorrência do dano, visa-se a sua reparação.

Nota-se os dois núcleos:

a) primeiro momento: é o de internalizar os custos da prevenção, vislumbra-se elementos de economia para dar subsídio ao seu conteúdo. Assim, nesse momento busca-se aplicar ao poluidor o ônus de arcar com as despesas de prevenção. A sua implementação se dá através de incentivos à introdução de tecnologia menos poluidora e

\footnotetext{
${ }^{20} \quad$ PRIEUR, Michel. Droit de l'environnement. 3. ed. Paris: Dalloz, 1996 apud MILARÉ, op. cit., p. 39, nota 9.

21 MILARÉ, op. cit., p. 43, nota 9.

22 TUPIASSU, op. cit., p. 168, nota 20.
} 


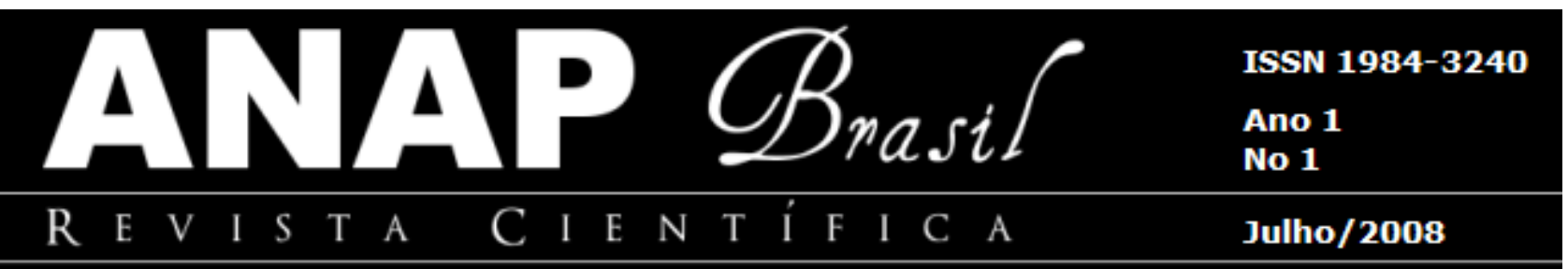

mais avançada, além de minimizar o custo administrativo e o tempo de aplicação de sanções. "Internalizando as extremidades ambientais negativas por elas produzidas, traduzidas nos gastos necessários à diminuição, eliminação ou neutralização dos danos." ${ }^{23}$

A internalização das externalidades, "representadas pelos custos,

benefícios ou implicações que as atividades de um determinado ente impõem a outrem ou à coletividade"24, faz-se necessária a aplicação jurídico-contábil, criando o denominado passivo-econômico-ambiental, uma vez que o usuário-pagador utiliza-se dos recursos ambientais como insumos.

b) O segundo momento: é o da responsabilização efetiva pelo dano causado, ou seja, ocorrendo danos ao meio ambiente em razão da atividade desenvolvida, o poluidor será responsável pela sua reparação.

"A realização dessa diretriz é um fator necessário para a efetivação do direito constitucional a um meio ambiente ecologicamente equilibrado." 25

Voltando-se especificamente para o caso brasileiro, nota-se que, embora o legislador não tenha consagrado expressamente o princípio do "poluidor-pagador", o certo é que se observa um evidente afloramento desse princípio no art. $4^{\circ}$, VI, da Lei da Política Nacional do Meio Ambiente, quando prevê a "imposição, ao poluidor e ao predador, da obrigação de recuperar e/ou indenizar os danos causados". Além disso, vários outros diplomas legais, como por exemplo, a Lei da Ação Civil Pública e a própria Constituição Federal, que reconhecem, na prática, primado do princípio do "poluidor-pagador".

O princípio do poluir pagador está instrumentalizado na Constituição Federal no artigo 225, $\S 3^{\circ}$, que reza: "As condutas e atividades lesivas ao meio ambiente sujeitarão os infratores, pessoas físicas ou jurídicas, a sanções penais e administrativas, independentemente da obrigação de reparar os danos causados."

Criou-se ainda, uma novidade na questão da responsabilidade - criou-se a responsabilização objetiva ambiental que tem a sua origem no artigo 13 da Declaração de Estocolmo e, posteriormente, foi insculpida na Lei de Política Ambiental - instituindo a tríplice responsabilidade ao poluidor, nos âmbitos do direito civil, administrativo e também criminal.

23 DERANI, op. cit., p. 158, nota 79.

24 TUPIASSU, op. cit., p. 166, nota 20.

25 DERANI, op. cit., p. 164 , nota 78. 


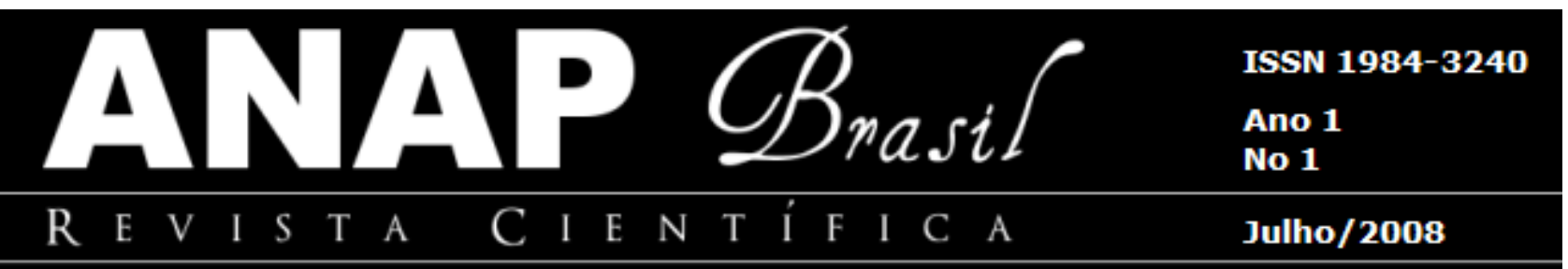

A Lei 6938/81, em seu art. 14, parágrafo $1^{\circ}$ dispõe: "é o poluidor obrigado, independentemente de existência de culpa, indenizar ou reparar os danos causados ao meio ambiente e a terceiros, afetados por sua atividade"

Para exprimir o aspecto econômico desse princípio, utiliza-se das palavras de José Renato Nalini:

Algo é certo. Estados-nação desenvolvidos já concluíram ser muito menos dispendioso prevenir um custo ambiental, impedindo que o dano se verifique, do que arcar com os prejuízos posteriormente. Sem dizer que há perdas irreparáveis, que vão para a coluna da insolvência, dentre os débitos sociais e éticos do país. ${ }^{26}$

\section{CONCLUSÃO}

Os princípios de Direito Ambiental estão inseridos dentro de todo o ordenamento jurídico. Observa-se a sua constitucionalização através da Carta Política de 1988 e amplamente presente nas normas infraconstitucionais.

Somos notáveis pela importância que os princípios de Direito Ambiental representam no ordenamento jurídico, contudo, a sua efetividade e aplicação apresentase ainda, mas tímida e pouco eficaz diante da sua magnitude.

Por outro lado há um total desconhecimento dos princípios ambientais por toda a sociedade, ainda que o Princípio da Educação Cooperação e da Educação Ambiental estejam presentes no rol dos princípios de ordem constitucional.

Urge que referidos princípios e sua forma de implementação prática, através dos instrumentos legais oferecidos, tornem-se cada vez mais presentes no dia-dia da sociedade para uma efetiva proteção ao meio ambiente.

.A desmistificação deste universo se faz premente posto que o meio ambiente sadio e equilibrado é um direito e também um dever de todos.

Há que se utilizar das ferramentas técnicas para a aplicação prática dos princípios, de forma a inseri-los na contextualização da sociedade como um todo. Atitudes modestas, de cunho simples fazem a diferença em seu conjunto, tais como a

\footnotetext{
26 NALINI, op. cit., p. XIX, nota 45.
} 


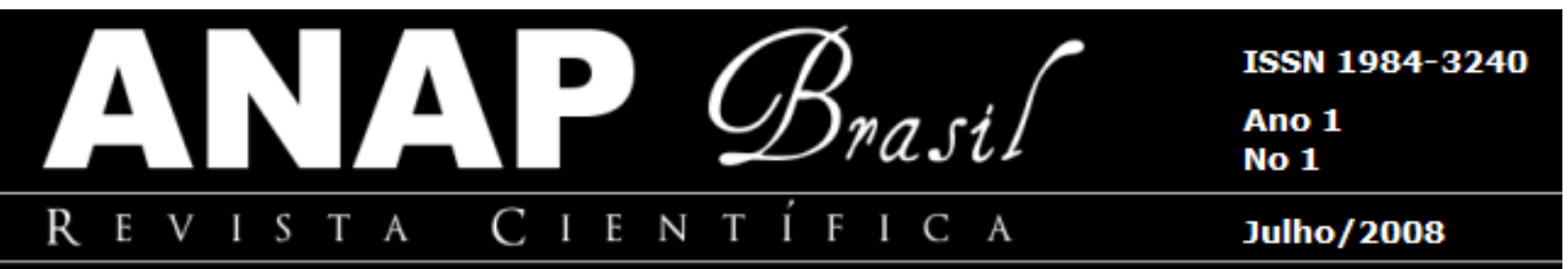

coleta seletiva dos lixos urbanos, tornando possível a reciclagem dos mesmos, a econômica de energia e organização quanto ao consumo de água.

Hodiernamente é ainda muito inexpressiva a atuação da sociedade no que pertine a uma participação efetiva em audiências públicas ambientais, com suas articulações e ações em defesa do meio ambiente através das atuações do terceiro setor.

Quanto aos agentes políticos há ainda uma profunda e ineficaz aplicabilidade dos princípios constitucionais, tanto pelo desconhecimento quanto pelo descaso público. Mesmo neste cenário caótico apresentado pela recente publicado $4^{a}$ relatório do IPCC Painel Intergovernamental de Mudanças Climáticas, indicando o impacto das mudanças climáticas, esta é ainda ignorada pelos programas diretamente ligados ao meio ambiente.

Até os planos nacionais de diferentes ministérios não incorporam projeções e medidas sobre mudanças climáticas.

Ora, é imperiosa a mudança de paradigmas e conceitos ambientais.

A Educação ambiental exerce neste cenário um papel primordial na disseminação do conhecimento, do despertar da consciência ecológica, da ética ambiental. Somente o conhecimento e a sua interiorização despertará na sociedade o desejo de preservação como forma de manutenção da espécie e da própria vida humana.

Assim, para que o Direito Ambiental tenha aplicabilidade e efetividade é de capital importância que, além das leis seja também do senso comum seus princípios fundamentais, pois, como normas de valor genérico orientarão a sua compreensão, aplicação e integração do sistema jurídico como um todo.

\section{REFERÊNCIAS}

BENJAMIN, Antonio Herman V. Introdução ao direito ambiental brasileiro. Revista de Direito Ambiental, São Paulo, ano 4, n. 14, p. 48-82, abr./jun. 1999.

Dano ambiental: prevenção, reparação e repressão. São Paulo: Revista dos Tribunais, 1993. 


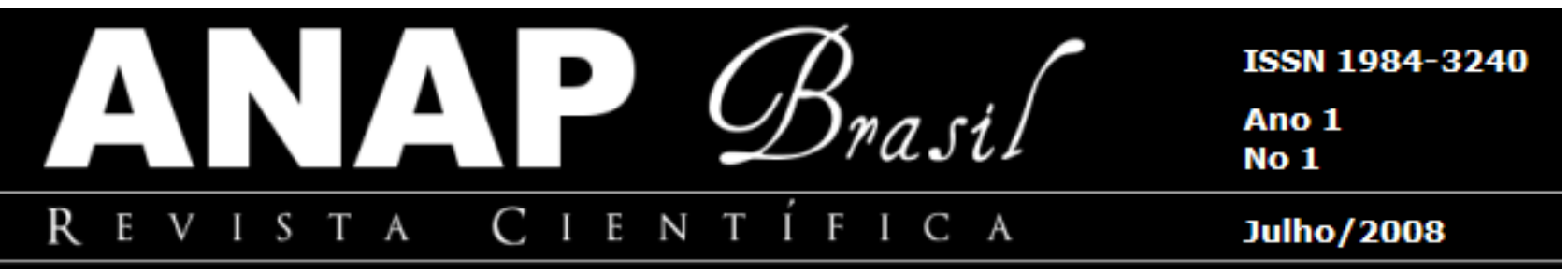

Reflexões sobre a hipertrofia do direito de propriedade na tutela da reserva legal e das área de preservação permanente. Revista de Direito Ambiental, São Paulo, ano 1, n. 4, p. 41-60, out./dez. 1996.

BRASIL. (Constituição 1988). Constituição da República Federativa do Brasil. Brasília: Senado Federal, 1988.

BRASIL. Lei n. 4.504, de 30 de novembro de 1964. Estatuto da Terra. Diário Oficial da União, Brasília, 30 nov. 1964.

CRETELLA JÚNIOR, Comentários à Constituição brasileira de 1988 . Rio de Janeiro: Forense Universitária, 1989. v. 1.

DERANI, Cristiane. Direito ambiental econômico. São Paulo: Max Limonad, 1997.

DERANI, Cristiane. A propriedade na Constituição de 1988 e o conteúdo da "função social”. Revista de Direito Ambiental, São Paulo, ano 7, n. 27, p. 58-69, jul./set. 2002.

FIORILLO, Celso Antonio Pacheco. Curso de direito ambiental brasileiro. 3. ed. São Paulo: Saraiva, 2002.

FIORILLO, Celso Antonio Pacheco; RODRIGUES, Marcelo Abelha. Manual de direito ambiental e legislação aplicável. São Paulo: Max Limonad, 1997.

MACHADO, Paulo Afonso de Leme. Direito ambiental brasileiro. 8. ed. Rio de Janeiro: Revista dos Tribunais, 2000.

. Rio + 10, Estocolmo + 30: novos rumos. Revista de Direito Ambiental, São Paulo, ano 6, n. 23, p. 385-392, jul./set. 2001.

MILARÉ, Édis. Direito do ambiente. São Paulo: Revista dos Tribunais, 2000.

Direito do ambiente: um direito adulto. Revista de Direito Ambiental, São Paulo, ano 4, n. 15, p. 34-55, jul./set. 1999.

MIRRA, Álvaro Luiz Valery. Direito ambiental: o princípio da precaução e sua aplicação judicial. Revista de Direito Ambiental, São Paulo, ano 6, n. 21, p. 92-102, jan./mar. 2001.

Princípios fundamentais de direito ambiental. Revista de Direito Ambiental, São Paulo, ano 1, n. 2, p. 50-66, abr./jun. 1996.

NALINI, José Renato. Ética ambiental. Campinas: Millennium, 2001.

NAZO, Georgette Nacarato; MUKAI, Toshio. O direito ambiental no Brasil: evolução histórica e a relevância do direito internacional do meio ambiente. Revista de Direito Ambiental, São Paulo, ano 7, n. 28, p. 70-100, out./dez. 2002. 


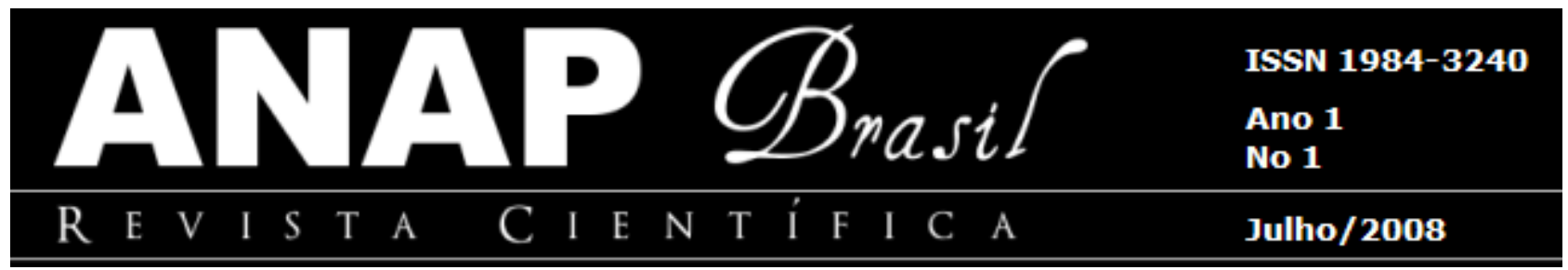

SOARES, Guido Fernando Silva. Direito internacional e meio ambiente: emergência, obrigações e responsabilidades. São Paulo: Atlas, 2001.

SOUZA, Joaquim Augusto Azevedo. Reserva legal é igual a confisco. O Diário, Ribeirão Preto, 5 jul. 1998. p. 7.

TRINDADE, Antônio A. Cançado. Proteção internacional dos direitos humanos. São Paulo: Saraiva, 1991.

Direitos humanos e meio ambiente: paralelo dos sistemas de proteção internacional. Porto Alegre: Sérgio Fabris Editor, 1993.

TUPIASSI, Lise Vieira da Costa. O direito ambiental e seus princípios informativos. Revista de Direito Ambiental, São Paulo, ano 8, n. 30, p. 155-178, abr./jun. 2003. 